\title{
Strumpell's pure familial spastic paraplegia: case study and review of the literature
}

\author{
GR E G OR Y L. HOLMES A N D B N NET T A. SHA Y I T Z \\ From the Departments of Pediatrics and Neurology, Yale University School of Medicine, \\ New Haven, Connecticut, USA
}

SUMMARY A family with pure Strumpell's familial paraplegia is presented. There were 11 afflicted members involving three generations. The mode of inheritance was dominant, the onset in the first decade, and in this family the disease was mild. Literature data from 104 families with 536 members dating from 1880 are tabulated. This report confirms others regarding mode of inheritance, age of onset, distribution between sexes, and disease manifestations. However, contrary to other reports, we found the dominant and recessive form of pure Strumpell's familial spastic paraplegia to be similar in severity. There are now clinical and pathological data supporting the separation of pure Strumpell's familial spastic paraplegia from the other heredodegenerative diseases of the nervous system.

Credit for the first description of familial spastic paraplegia is usually given to Strumpell (1880) although a very similar condition was described by Seeligmüller (1876) four years earlier. Strumpell's original description was of a rare hereditary disorder characterised by progressive weakness and spasticity of the lower limbs with little or no involvement of the upper extremities.

However, there has been controversy about the relationship between familial spastic paraplegia and other heredofamilial diseases of the nervous system. Many authors have argued that the term familial spastic paraplegia should include a variety of related diseases, and in the almost 100 years since Strumpell's original case report there has been extensive reporting of many forms of the disorder. Other authors such as Bickerstaff (1950), Ozsvath (1968) and Behan and Maia (1974) have felt that the disease originally described by Strumpell remains a distinct clinical and pathological entity. It is the purpose of this paper to review a family with 'pure' familial spastic paraplegia and review all such cases reported in the literature to date.

\footnotetext{
Supported by USPHS Grant (NS 12384). A list of the published cases accepted by the authors as true cases of Strumpell's familial spastic paraplegia can be obtained from each author.

Address for correspondence and reprint requests: Dr Bennett $A$. Shaywitz, Pediatric Neurology, Yale University School of Medicine, New Haven, Connecticut 06510, USA.

Accepted 24 May 1977
}

\section{Case presentation}

CASE 1 (INDEX PATIENT)

KF (Figure), a 7 year old white male, was in his usual state of good health until six months before admission when his mother noticed the onset of difficulty negotiating stairs, with more trouble going up than down. The symptoms increased minimally in severity during the six months before hospitalisation. The defect was not incapacitating as the patient could still run and was quite active. He denied any history of paraesthesias, sensory loss, poor sphincter control, or upper extremity difficulty. Developmental milestones had been normal. The patient's uncle was diagnosed as having hypertrophic muscular dystrophy at age 17 years and has subsequently had a non-progressive spastic gait, and his great uncle's son as having Charcot-Marie-Tooth disease at age 6 years with subsequent non-progressive abnormal gait. Several other family members were said to have 'spring gaits'.

General physical examination was normal. Neurological examination indicated normal percentiles for height and weight. All cranial nerves were functioning normally. Light touch, pain, hot/ cold, vibratory and position sensory modalities were within normal limits. The patient had normal deep tendon reflexes in the upper extremities but had $4+$ knee, adductor, and hamstring reflexes, and 5+ Achilles reflex. Abdominal and 


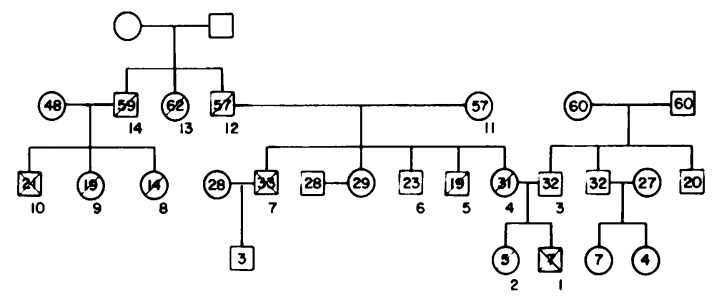

[. (2) Full expression of diseose

$\square \bigcirc$ Mild defect

Figure Pedigree of family described in text. Numbers adjacent to family members correspond to description in text. Numbers within box or circle indicate age.

cremasteric reflexes were normal. The patient had a negative Hoffmann's sign but bilateral extensor plantar reflexes. Muscle tone and mass were normal. There was decreased power of the iliopsoas and dorsiflexors of the feet bilaterally. The patient walked well on his toes but had some difficulty with heel walking. Romberg's sign was absent. The gait was stumbling and wide based.

Laboratory tests in the hospital consisted of a complete blood count, serum electrolytes, calcium, phosphate, creatine phosphokinase, glucose, skull radiographs, and EEG, all of which were normal. A lumbar puncture revealed an opening pressure of $150 \mathrm{~mm}$ of water; the CSF contained no red or white blood cells and had a protein level of $0.04 \mathrm{~g} / \mathrm{l}$. A cervical and lumbar myelogram were within normal limits. Tibial and peroneal nerve conduction studies were within normal limits. A muscle biopsy, taken from the quadriceps muscle, with $\mathrm{H}$ and $\mathrm{E}$ stain, revealed no abnormalities other than a slight increase in variability of the fibre diameters. The Gomorri trichrome preparation of the frozen material was unremarkable. NADH and menadione linked alpha glycerophosphate (MAG) dehydrogenase stains revealed no remarkable enzyme abnormalities. Most of the biopsy sample showed large groups of fibres staining dark with the NADH dehydrogenase and staining lightly with the MAG dehydrogenase. No small group atrophy or angular atrophic fibres were noted. It was felt that the histochemical studies were indicative of a neurogenic process.

The patient was discharged with the diagnosis of familial spastic paraplegia and was started on physical therapy. Follow-up six months after discharge revealed no progression of his disease. Several other members of the family were examined.
CASE 2

The index patient's sister walked at 13 months and appeared well until the mother noticed the child having difficulties in gym class where she began stumbling frequently and developed a wide based gait. Her deep tendon reflexes were increased in the knees with unsustained clonus in the ankles bilaterally. Her plantar responses were flexor bilaterally. The gait was wide based and the patient had difficulty walking on her heels, but she could walk well and had no sensory loss, weakness, atrophy, pain, or ataxia.

\section{CASE 3}

The patient's father denied any difficulty with gait and neurological examination was normal.

\section{CASE 4}

The patient's mother had no obvious defect in her gait but did complain of tiredness in the legs frequently. Neurological examination demonstrated hyperreflexic knee and ankle reflexes with flexor plantar responses and weakness of hip and ankle flexors.

CASE 5

A maternal uncle denied any difficulty with gait. He had a normal gait, hyperreflexic lower extremities, and flexor plantar responses.

CASE 6

A brother of case 5 denied any difficulty with gait, and physical examination was entirely within normal limits.

\section{CASE 7}

Another maternal uncle of the index patient had a normal childhood with normal developmental milestones until age 6 years when it was noted that he began to walk with a limp. His main difficulty was in negotiating stairs and he frequently stumbled going down stairs. At age 16 years he was noted to have hyperreflexic lower extremities with extensor plantar responses and mild lower extremity muscle wasting. A myelogram was normal and a muscle biopsy specimen was interpreted as being consistent with muscular dystrophy but not diagnostic of that disorder. The disease did not progress and when seen by us at age 33 years he had a limp with a slightly wide based gait. He had remained quite mobile; however, he could not run for any distance over a few metres. He denied any upper extremity problems, sensory loss, sphincter difficulties, or pain in the lower extremities. Physical examination revealed hyperreflexic lower extremities with clonus of the ankles and plantar 
extensor responses bilaterally. There was no sensory loss, upper extremity involvement, ataxia, or muscle wasting.

\section{CASE 8}

Case 8 denied any difficulty with gait. On physical examination she had a normal gait, hyperreflexic lower extremities, and flexor plantar responses.

\section{CASE 9}

The sister of case 8 denied any difficulty with gait. On physical examination she had a normal gait, hyperreflexic lower extremities, and bilateral extensor plantar reflexes.

\section{CASE 10}

The brother of 8 and 9 had a normal childhood with normal developmental milestones until approximately age 6 years when it was noted that he had a slightly waddling gait with clumsiness. Neurological examination at that time showed hyperreflexic lower extremities with extensor plantar reflexes, tight Achilles tendon, and gastrocnemius muscle wasting. A diagnosis of Charcot-Marie-Tooth disease was made. When seen by us at age 21 years, his disease had not progressed. He continued to walk with a slight limp and wide based gait. Physical examination was within normal limits except for hyperreflexic lower extremities with extensor plantar reflexes. He had minimal muscle wasting without ataxia, weakness, or sensory loss.

\section{CASE 11}

The grandmother of the index patient denied any difficulty with gait. Physical examination was entirely within normal limits.

\section{CASE 12}

The patient's grandfather had a normal gait but complained that he occasionally had lower extremities weakness and he had hyperreflexic knees and ankles with bilateral extensor plantar responses.

\section{CASE 13}

The great aunt of the patient denied any difficulty. On physical examination she had a normal gait but hyperreflexic knees and ankles with flexor plantar responses.

\section{CASE 14}

The patient's great uncle denied any difficulties with his gait. He had a normal neurological examination except for hyperreflexic lower extremities with bilateral extensor plantar responses.

\section{Discussion}

Since Strumpell, pure cases of familial spastic paraplegia have been few. Rhein (1916) reviewed 111 families reported in the literature while in 1933 Paskind and Stone found 153 families in their literature search. Price (1939) brought the total number of cases to 158 families. Bell and Carmichael (1939) could find only one case of pure familial spastic paraplegia after reviewing the records from two large London hospitals over a period of 20 years although they did publish results from a review of 74 cases found in the literature. Bickerstaff (1950), Schwarz (1952), Behan and Maia (1974) and other authors have subsequently published other cases but the most extensive review of the world literature to date has been by Ozsvath (1968) who found 142 cases of what he described as pure familial spastic paraplegia. Ozsvath defined his pure cases as those in which there were only intensified reflexes, spastic muscle tone, and spastic gait as originally described by Strumpell. Occasional patients described by Ozsvath had associated neurological deficits such as mental retardation, optic atrophy, and sphincter disorders. No patients with cerebellar or extrapyramidal disorders were included in his 'pure' cases. Using more stringent criteria we have reviewed the world literature and found a total of only 104 cases of a hereditary disorder characterised by progressive weakness and spasticity of the lower limbs. If there were any other neurological disorder which appeared to recur in the families they were not included in this review. Several families included in other authors' reviews were not used because of insufficient clinical information in the original report.

Strumpell classified his cases in two groups according to the age of onset of the disease. In group one, the onset of disease occurred between the third and sixth years of life, while in group two onset was later, occurring between the twentieth and thirtieth years. Bell and Carmichael also divided their cases into two groups, autosomal recessive and dominant, roughly corresponding to Strumpell's two groups, and we have used this classification in our review. Like Bell and Carmichael we were able to divide all the cases into dominant and recessive forms. Two families reported by Johnston and McKusick (1962) and Baar and Gabriel (1966) of familial spastic paraplegia where the pedigrees were compatible with $x$-linked recessive inheritance were not true cases of pure spastic paraplegia as both families had early signs of brain stem and cortical lesions. 
The dominant form was noted in 73 out of 104 families $(70 \%)$ while the recessive was seen in 31 out of $104(30 \%)$. There were a total of 441 family members described in the dominant form, 95 in the recessive type. The dominant form has usually been characterised by a wide variation in the age of manifestation, slowness of progression, and relative rarity of devastating neurological deficit whereas the recessive type has an early beginning and a generally more severe course. In the recessive cases reviewed by Bell and Carmichael (1939) there was an earlier onset (10.9 and 12.3 years for males and females respectively) than the dominant type (18.5 and 18.7 years respectively for male and female) and a more rapid progression of the disease. They also noted that while the dominant type often did not occur until middle age it was rare to see the onset of the recessive type after the age of 10 years. Our data confirmed their analysis. Of the 31 cases of autosomal recessive cases of pure familial spastic paraplegia in the literature, 23 out of $31(74 \%)$ had onset in the first decade while only 43 of $73(59 \%)$ cases of the dominant form had onset in the first decade. However, because the dominant form can be very mild it is quite possible that many members of the families reported could have had subclinical manifestations. For example, in the case presented here the patient's mother may have had corticospinal tract findings in the first decade but because her gait was not noticeably abnormal this may not have come to medical attention at that time.

Analysis of the cases recorded by Bell and Carmichael (1939) revealed a high sib/sib correlation of age at onset within families; our review again supports these observations. In the 104 cases of pure familial spastic paraplegia reviewed intrafamilial homochrony (within a decade) was found in 82 families. Again it was the recessive type which had the most intrafamily homochrony; $78 \%$ of the families had onset of the disease within one generation, $100 \%$ within two generations. Only $64 \%$ of the cases with the dominant mode of inheritance had onset within one decade.

As in previous studies males outnumber females in both forms, $57 \%$ to $43 \%$ in the dominant form, $61 \%$ to $39 \%$ in the recessive type.

Although the extent and severity of the disease among families varies from mild hyperreflexic lower extremities with a slightly abnormal gait to a severe crippling illness, the disease tends to follow similar clinical courses within families. For purposes of comparison, severity of the disease in each family member was ranked from 1 to 4 with
1 equal to no clinical abnormality, with increased refiexes in the lower extremities, and/or plantar extensor responses, 2 equal to mild gait abnormality, 3 equal to a severe gait abnormality hindering activities, requiring crutches, or both, and 4 equal to disease to such an extent that the patient is bedridden. Severity was similar in both groups, averaging 2.7 in the recessive and 2.5 for the dominant.

Because of the generally benign course of the disease there are few pathological data. Schwarz's (1952) review of the literature produced only seven cases with pathological specimens from cases which fit the original clinical description of Strumpell's familial spastic paraplegia. Schwarz and Liu (1955) reported on another case, and Behan and Maia (1974) added two more cases to the literature in 1974 bringing the total with pathological specimens to 11 cases. They reported that all cases to date of the pure form show similar patterns-corticospinal tract degeneration from the medullary pyramids downward, increasing caudally, and posterior column degeneration, without loss of posterior root fibres, increasing rostrally. Behan and Maia felt that Strumpell's familial spastic paraplegia is a well defined pathological and clinical entity and should be separated from the numerous 'system' degenerations.

The number of associated neurological symptoms that have been added to the relatively specific entity described by Strumpell continues to grow and make analysis of the cases difficult. Variants of familial spastic paraplegia have included familial spastic paraplegia with spinocerebellar artrophies such as Friedreich's ataxia and Charcot-MarieTooth disease (Ross, 1942), ataxia (Bell and Carmichael, 1939), dementia (Paskind and Stone, 1933; van Bogaert, 1952), visual defects (Crowe, 1944), mental deficiency (Paskind and Stone, 1933; Gamboa and Peniche, 1973), central retinal degeneration (Kjellin, 1949; Jéquier and Streiff, 1947), ichthyosis (Sjögren and Larsson, 1957), sensory impairment (Koenig and Spiro, 1970), extrapyramidal features (Dick and Stevenson, 1953), cardiac conduction defects (Sutherland, 1957), optic atrophy (Ozsvath, 1968), epilepsy (Bruyn and Mechelse, 1962), retrobulbar neuritis (Bickerstaff, 1950), amyotrophy (Holmes, 1905; Garland and Astley, 1950; Refsum and Skillicorn, 1954; Gilman and Horenstein, 1964), leucodystrophy (Poser et al., 1957), and Huntington's chorea (Frank and Vuia, 1973). Of 267 families with familial spastic paraplegia, Ozsvath noted that $57 \%$ were associated with other defects: cerebellar symptoms in $23 \%$, amyotrophic lateral 
sclerosis in $17 \%$, extrapyramidal symptoms in $7 \%$, and optic atrophy in $8 \%$.

Rhein (1916) was the first to point out that forms exist between pure spastic paraplegia, familial amyotrophic lateral sclerosis, familial cerebral diplegia, and familial disseminated sclerosis. Since Rhein, many other authors including Ross (1942) and Landau and Gitt (1951) have emphasised the interweaving of patterns in certain of the heredodegenerative diseases notably the Friedreich's complex, Charcot-Marie-Tooth disease, Roussy-Lévy syndrome, familial spastic paraplegia, and feel that in some families there may be genetic vulnerability of certain tracts in the CNS to degeneration in either a simple or complex fashion producing mild or complicated neurological disturbances.

Although it is interesting to speculate about possible interrelationships among the disease groups mentioned above it appears quite clear to us that there is indeed a separate, albeit rare, clinical entity of pure Strumpell's familial spastic paraplegia with its unique modes of inheritance, clinical course and pathology.

\section{References}

Baar, H. S., and Gabriel, A. M. (1966). Sex-linked spastic paraplegia. American Journal of Mental Deficiency, 71, 13-18.

Behan, W. M. H., and Maia, M. (1974). Strümpell's familial spastic paraplegia: genetics and neuropathology. Journal of Neurology, Neurosurgery, and Psychiatry, 37, 8-20.

Bell, J., and Carmichael, E. A. (1939). On hereditary ataxia and spastic paraplegia. In Treasury of Human Inheritance. Cambridge University Press: London.

Bickerstaff, E. R. (1950). Hereditary spastic paraplegia. Journal of Neurology, Neurosurgery, and Psychiatry, 13, 134-145.

Bruyn, G. W.. and Mechelse, K. (1962). The association of familial spastic paraplegia and epilepsy in one family. Psychiatria, Neurologia. Neurochirurgia, 65, 280-292.

Crowe, M. P. (1944). Family spastic paresis with strabismus. Archives of Disease in Childhood, 19, 32-33.

Dick, A. P.. and Stevenson, C. J. (1953). Hereditary spastic paraplegia. Report of a family with associated extrapyramidal signs. Lancet, 1, 921-923.

Frank, G., and Vuia, O. (1973). Chorea HuntingtonAmyotrophic Lateralsklerose-Spastische Spinal paralyse. Zur Kombination von Systemkrankungen. Zeitschrift für Neurologie, 205, 207-220.

Gamboa, I., and Peniche, J. H. (1973). Diplejia espástica familiar estudio de una familia mexicana. Revista de Investigación Clinica. 25, 47-50.

Garland. H. G., and Astley, C. E. (1950). Hereditary spastic paraplegia with amyotrophy and pes cavus. Journal of Neurology, Neurosurgery, and Psychiatry, 13, 130-133.

Gilman, S., and Horenstein, S. (1964). Familial amyotrophic dystonic paraplegia. Brain, 87, 51-66.

Holmes, G. (1905). Familial spastic paralysis associated with amyotrophy. Review of Neurology and Psychiatry, 3, 256-263.

Jéquier, M., and Streiff, E. B. (1947). Paraplégia dystrophie squelettique et dégenéréscence tapétorétinienne familiales. Archiv der Julius Klaus Stiftung für Vererbungsforschung, Sozialanthropologie and Rassenhygiene, 22, 129-167.

Johnston. A. W., and McKusick, V. A. (1962). A sex linked recessive form of spastic paraplegia. American Journal of Human Genetics, 14, 83-94.

Kjellin, K. (1949). Familial spastic paraplegia with amyotrophy, oligophrenia, and central retinal degeneration. Archives of Neurology (Chicago), 1, 133-140.

Koenig, R. H., and Spiro, A. J. (1970). Hereditary spastic paraparesis with sensory neuropathy. Developmental Medicine and Child Neurology. 12, 576-581.

Landau, M., and Gitt, J. J. (1951). Hereditary spastic paraplegia and hereditary ataxia. A family demonstrating a variety of phenotypic manifestations. Archives of Neurology and Psychiatry (Chicago). 66, 346-354.

Ozsvath, K. (1968). Paralysis spinalis spastica familiaris. Deutsche Zeitschrift für Nervenheilkunde, 193, 287-323.

Paskind, H. A., and Stone, T. T. (1933). Familial spastic paralysis. Archives of Neurology and Psychiatry (Chicago), 30, 481-500.

Poser, C. M., Dewulf. A., and van Bogaert. L. (1957). Atypical cerebellar degeneration associated with leukodystrophy. Journal of Neuropathology and Experimental Neurology, 16, 209-237.

Price, G. (1939). Familial lateral sclerosis (spastic paralysis. Journal of Nervous and Mental Diseases, 90, 51-55.

Refsum, S., and Skillicorn. S. A. (1954). Amyotrophic familial spastic paraplegia. Neurology (Minneapolis), 4, 40-47.

Rhein, J. W. (1916). Family spastic paralysis. Journal of Nervous and Mental Diseases, 44, 115-144.

Ross. A. (1942). Combination of Friedreich's ataxia and Charcot-Marie-Tooth atrophy in each of two brothers. Journal of Nervous and Mental Diseases, 95, 680-681.

Schwarz, G. A. (1952). Hereditary (familial) spastic paraplegia. Archives of Neurology and Psychiatry (Chicago), 68, 655-682.

Schwarz, G. A., and Liu. C. N. (1955). Hereditary (familial) spastic paraplegia. Archives of Neurology and Psychiatry (Chicago). 29, 144-162.

Seeligmüller, A. (1876). Sklerose der Seitenstrange des Rückenmarks bei vier Kindern derselben Familie. Deutsche Medizinische Wochenschrift, 2, 185-186.

Sjögren, T., and Larsson. T. (1957). Oligophrenia in combination with congenital ichthyosis and spastic 
disorders. A clinical and genetic study. Acta Psychiatrica Scandinavica, 113, 1-112.

Strumpell, A. (1880). Beiträge zur Pathologie des Rückenmarks. Archiv für Psychiatrie und Nervenkrankheiten, 10, 676-717.

Sutherland, J. M. (1957). Family spastic paraplegia: its relationship to mental and cardiac abnormalities. Lancet, 2, 169-170.

van Bogaert, L. (1952). Etudes génétiques sur les paraplégies spasmodiques familiales. Journal de Génétique Humaine, 1, 6-23. 